\title{
Influence of Information Culture on Adoption of a Self-Service System
}

\author{
Bob Travica \\ University of Manitoba, Winnipeg, Canada
}

btravica@ms.umanitoba.ca

\begin{abstract}
This article discusses a qualitative case study of adoption of a self-service based human resources management system in a utilities company by taking a perspective of information culture. The main finding is that a number of specific cultural aspects evolving around information technology and information can help to explain why the adoption of the system reached just a moderate level. Contributions of the study to understanding self-service information systems and to system adoption theory and practice are discussed.
\end{abstract}

Keywords: Information system adoption, self-service system, ERP system, organizational culture, information culture

\section{Introduction}

This article reports on a case study of a self-service based human resources management system (HRMS) in a Utilities Company (code name) in Canada, by extending the adoption analysis beyond previously illuminated cognitive aspects (Travica, 2007). The self-service model of information systems (IS) requires end-users to manipulate the system entirely and directly, with no help from an intermediary. Cash machines, various online services (banking, travel, exchanges) and stores accessible via the Internet, and you-scan-it checkout systems in grocery stores are some of many examples of self-service information systems. The focus of this study is on the self-service IS that support organizations internally. Examples include the student course registration system by which students today choose courses without facing registration clerks, and desktop applications for cubing data warehouses. The elimination of intermediaries in using selfservice IS brings casual users to the foreground. These users can no longer count on help from specially trained users.

Jumping into the seat of primary user can challenge the accustomed ways of manipulating information and working. Acquiring a broader access to dat a can generally be considered a beneficial outcome (Bhappu \& Shultze, 2006; Curran, Meuter, \& Suprenat, 2003). Still, this benefit needs to be paid by the work of operating a computer software and hardware. While the balance in this

Material published as part of this publication, either on-line or in print, is copyrighted by the Informing Science Institute. Permission to make digital or paper copy of part or all of these works for personal or classroomuse is granted without fee provided that the copies are not made or distributed for profit or commercial advantage AND that copies 1 ) bear this notice in full and 2) give the full citation on the first page. It is permissible to abstract these works so long as credit is given. To copy in all other cases orto republish or to post on a serveror to redistribute to lists requires specific permission and payment of a fee. Contact 0HPublisher@InformingScience.org to request redistribution permission. case is likely to be on the benefit side, the benefit differential may diminish when an increment in work is associated with less certain benefits. For example, a doctor that directly enters prescriptions in an electronic medical record system has lost the convenience of having a nurse record orally-conveyed prescriptions and may be losing time that otherwise would be allocated to diagnostic and other eminently professional work 
(cf. Lapointe \& Rivard, 2005). Furthermore, as any other IS, a self-service system must be easy to use in order to achieve a higher adoption rate (Davis, 1989). This principle becomes even more urging with self-service IS because these typically employ some enterprise resource planning (ERP) software that usually is difficult or too expensive to supply with an easy to use user interface. Another consequence of an enterprise system is that the processes it supports cut across organizational functions. If the process owner is clearly defined, this owner cannot have authority over system adopters in otherthan his/her area of responsibility (e.g., human resources, or marketing). If the process owner is not clearly defined due to inter-departmental tensions (say, a process spans over the marketing and sales department), system adoption at large is rendered to a laissez faire. In either scenario, the enforcement of self-service system adoption is unravelled. Moreover, while supporting a larger and diverse body of users, the process of adoption a selfservice system can trigger creation of elaborate mental imagery that is nearly impossible to control, and some of this imagery can work against adoption efforts (T ravica, 2007).

The discussion above out lines the space of a new research problem the importance of which is likely to grow with increasing use of self-service systems: What are the key factors in adopting intra-organizational self-service systems? The study presented here addressed this problem by investigating a self-service HRMS based on Enterprise Resource Planning (ERP) soft ware by SAPTM .

While there is no direct literat ure support for this particular topic, the topic references several established segments of literature. These include the literat ure on ERP systems (e.g., Bulkeley, 1996; Krumbholz \& Maiden, 2001; Markus \& Tanis, 2000), self-service variants of ERP and other enterprise systems (Lapointe \& Rivard, 2005; Larsen \& Myers, 1999; Stein, Hawking, \& Wyld,, 2005), systems adoption theory (Davis, 1989; Rogers, 2003), and self-service technology in the extra-organizational cont ext (Bhappu \& Shultze, 2006; Curran et al., 2003; Dabholkar, Bobbitt, \& Lee, 2003). Still, the problem of the key factors playing part in adoption of intraorganizational self-service systems is new and it requires focused investigation that draws on relevant literat ure and takes research a step further to reach new insights. Seeking such new insights, the study has deployed a new conceptual and analytical framework called Information View of Organization (IVO) (Travica, 2005b). This article reports on applying a part of the IVO framework that is labeled "infoculture."

\section{Organization and System under Study}

Utilities Company provides electricity and gas to a particular regional market in Canada and exports electricity to the United States. The company is government-owned and based on a bureaucrat ic model. It belongs to larger organizations in Canada and employs numerous categories of white- and blue-collar workers. The central IS function numbers about 350 employees, $20 \%$ of which work in the SAP department. A transformation the company has been going through in recent years includes centralization of the HR function. An officially announced goal is to reduce gradually administrative staff. HR specialists have been moved away from divisions into a central function from which they are supposed to support divisions of the corporation. HR professionals provide consultation on HR matters for divisional management (managers and supervisors), while HR clerks help the HR professionals as well as divisions directly (e.g., they staff a help desk for HRMS).

The system studied is a mySAPTM self-service application for HR management. It contains two modules. One is for all employees to enter and query their time, expenses, travel, and professional development (this one will be labeled "SSE" after the term "self-service for employees"). Another module is intended for managers, to make online approvals of employees' reports, claims, and requests. This is SSM - self-service for managers. Managers can also print built-in reports and view professional profiles. Of course, manages are also users of SSE. The output from SSE 
feeds into SSM. Technically, SSE is just a new user interface that is layered atop of a core R/3 SAP technical system and runs on a SAP portal. The older system with nearly the same functionality accesses the R/3 system via Web forms. It was implemented a few years ago as a part of a non-self-service system used exclusively by clerks for administering time and expense data.

Within SSM, supervisors and managers are supposed to directly lookup reported time and expense data, approve it electronically, and create summary reports. It is assumed that managers would not let the clerks access HRMS and thus help managers in the approval process because this would compromise the security of sensitive dat a that only managers are authorized to see. In the division of labor established with the introduction of HRMS, 700 managers are supposed to use SSM.

\section{Adoption of Self-Service ERP: Terra Incognita}

The topic of adopting self-service systems has not been previously studied much, thus this study is charting a terra incognita. The general ERP literat ure has provided valuable insights into implementation situations, conditions, and effects. For example, Sarker and Lee (2000) found that adoption of an ERP system was associated with changes in the organization's old "dysfunctional culture" characterized by a "sea of paperwork," lack of communication between divisions, and scheduling errors. Krumbholz and Maiden (2001) found that implementation of SAP R/3 in a pharmaceutical firm did not fulfill the promises of achieving integrated data because the system was not configured uniformly across organizational units. Bulkeley (1996) discovered that a combination of unprecedented external difficulties and implementation mistakes (poor testing, insufficient user training, and a rushed rollout) was responsible for the disastrous effects of implementing, in a big-bang strategy, SAP modules at Fox-Meyer Drug. Markus and Tanis (2000) developed a process model of the ent ire experience firms pass through with an ERP system. This model has four phases - from planning to routine use. In between comes a "shakedown phase" that corresponds to system adoption. In this phase, a system goes live and users strive to achieve routine use or it may end up with a system shut down. Problems may occur during a shakedown, such as the maintenance of old processes, poor soft ware ease of use, stalled user skills, and low usage of system. A well-configured and int egrated system, redesigned business processes, trained users, resources to address problems, and action to fix problems are the main methods of overcoming the problems and securing successful adoption.

Being a new phenomenon, adoption of ERP-based self-service systems is less studied. Stein and colleagues (2005) identified a success story of a self-service-based application for pay, leave, and benefit packages in an Australian telecommunications firm. The authors reported a $40 \%$ reduction in administrative staffing, 80\% reduction in management HR duties, and $50 \%$ reduction of transaction costs. In contrast, Larsen and Myers (1999) discovered serious difficulties in the adoption of a SAP accounting module in a financial firm in New Zealand, where the accounts payable process was based on self-service. The difficulties involved skipping of BPR, lack of reports, and dissatisfied users. Although the number of accountants was reduced for $68 \%$, knowledge wa s lost with the fired employees, which resulted in low skill and morale. Finally, Lapointe and Rivard (2005) have found that enterprise systems may fail if the political position of a key user group is threatened. Doctors who were supposed to enter prescriptions into new electronic medical record systems rejected the systems in three of four hospitals in Quebec. The doctors managed to sustain their preferred manual method of dictating prescriptions to nurses, after criticizing the systems for imposing extra, non-professional work on them.

The problem of the present study also links to the theme of IS adoption. This is a well-established area of research that draws on behavioral theory and on models of innovation dissemination. The behavioral research focuses on predicting results of deliberations an individual user makes with regard to system adoption. For example, the well-known Technology Acceptance Model (Davis, 
Bagozzi, \& Warshaw, 1989) posits that users' perception of systems usefulness and of ease of use are antecedents to the user's intention to actually use the system. Self-service systems have not been addressed in T AM research. However, these systems may present new adoption challenges that demand fresh insights. Given the large size, complexity and partly a novice character of user groups, self-service systems may even require adjustments in the adoption theory. These premises set the foundations forthe case study of HRMS in Utilities Company.

\section{Methodology}

IVO approaches IS from the perspective that combines IS research, organization theory, and cognitive theory (for a more detailed explanation, please see Travica, 2005a, 2005b, 2007). The broad-based and flexible character of IVO made it a suitable theoretical foundation for investigating adoption of a self-service system in a qualitative fashion. Infoculture is one of elements of the IVO framework. It refers to beliefs (deep-set assumptions, values), behaviors and artifacts that are related to IT and information (knowledge, meaning, and data). This concept has a background in both IS theory and organization theory as few examples will demonstrate. Orlikowski and Gash (1994) identified influences of assumptions about instrumentality of IT and information in accomplishing performance goals in the organization they studied. In another study, Orlikowski (1996) discovered cultural assumptions, values, and st ories related to knowledge preservation. Bressand \& Distler (1995) assert ed that shared background knowledge could make a difference between organizational cultures. The choice of communication channels, methods of information sharing, and opting between facts and rumors impart distinguishing characteristics on organizations (Davenport \& Prusak, 1997). Sarker and Lee (2000) found that the proportion of electronic information processing vs. paperwork is a cultural aspect that implementation of ERP brings to the fore. Similarly, Travica (2005a) detected values attached to computers vs. paperwork that guided in different directions the thinking and action of polarized groups in a voluntary organization. The fragmentation of organizational culture and differing impacts of resulting sub-cultures have been linked to differences in IT adoption and use (e.g., Huang, Newell, Galliers, \& Pan, 2003). Recent developments in relevant theorizing include a cat egorization of IT cultures (KaarstBrown \& Robey, 1999) and modeling of relationships between group values, IT-related values, and values embedded in a specific IT (Leidner \& Kayworth, 2006).

This study was based on interpretivist epistemology and it followed a case study design (Lee, 1989; Yin, 2003). The case captures a six moth-period of adoption process of HRMS. Data were colleted in a triangulated manner. Intensive interviewing was the main method, combined with the author's hands-on experience of the system, observation of the system's use during some interviews, and document analy sis (the company's surveys of HRMS users' satisfact ion, HRMS plans and management reports, and broader corporate documentation). Interviewed were 33 persons in total, including four focus groups (11 respondents in total), which yielded 22 hours of interviews. Interviews were tape recorded with consent of the respondents, and notes were taken during each interview. With the exception of one focus group held via videoconferencing, interviews were face-to-face. Data collection and sampling started from an internal informant, and unfolded through snowballing and intentional sampling. The resulting sample exhibited variability in terms of professional background, hierarchy, and geographical location.

Design of interviews varied from open-ended to semi-structured, with the exception of the structured interview conducted with the CEO. An interview would start by asking a respondent to describe his/her main tasks and the role of HRMS in them. Then, probes would be used in order to learn about details of information and IT aspects involved in the tasks, and to elicit comparisons between the present and past. The respondent would also be prompted to speak of his/her feelings regarding the ups and downs of the new way of working and the system. If feasible, the respondent would be encouraged to use of HRMS in a typical or a troubling task. 
Coding was conducted during data collection, and included coding interview notes and transcripts, constant comparison of the codes, writing memos on code definitions, diagramming relationships between codes, and formulating emerging research questions. For most of the research process, coding was kept at a basic level by using common sense vocabulary and resisting aggregating categories into broader ones. Aggregation started when all the data were collected. The final step in coding was to match higher-level cat egories to IVO concepts (see the example below). This meant assigning the aggregated codes to the rubrics of infoculture and other IVO dimensions (not reported in this article). Many of these data analysis methods are used in different venues of qualitative research, such as ethnography (Orlikowski, 1992; Suchman, 1987; Tedlock, 2000) and grounded theory (Charmaz, 2006; Glasser \& Strauss, 1967).

\section{Good Information, Bad Technology, and Ugly Processes}

The study found that HRMS was only moderately adopted after about a year into what Markus and T anis (2000) call a "shakedown phase." The diagnosis of shakedown problems conceptualized by these authors indeed applies to HRMS: old processes are being maintained (and some are paper-based), software is not easy to use, users' skills are stalled, and there is a lower usage of the system. Evidence presented in this section speaks about uneven acceptance across the two HRMS applications, user groups, and IS aspects. This evidence is consistent with findings of several user surveys conducted in Utility Company, including one during this study. Zeroing in on the picture of adoption, SSE has faired better than SSM. Also, HR staff and clerks around the company have adopted SSM more than divisional management (managers and supervisors). This last and crucial user group truly challenges SSM. It also indirectly challenges HRMS since two modules are supposed to work in concert (data entered via SEE should be further processed in SSM).

The chief sell point of HRMS is data or information. Members of Utilities Company have expressed a notable appreciation of the content of both modules of HRMS. They have specifically praised direct access to personal information, the completeness of particular domain data (e.g., on professional training, banked hours, and available vacation time), a broader overall coverage of data on the managed staff, and thetimeliness of dat a that support decision making. For example, the managers interviewed concurthat the better coverage of staff data enables them to be better informed on their staff's characteristics and dynamics.

In contrast to the new information enabled by HRMS, the IT built into the system is mostly disliked. The IT stirs up dissatisfaction, frustration, grief, and anger. Usability problems are readily pointed to by almost all respondents. A lower usability plagues HRMS and is responsible for the users' disliking of the system. The criticism targets the system in general, screens (overloaded with details, limited in size, too wide so that horizontal scrolling must be applied, etc.), complicated use procedures, and some annoying system responses to user inputs (e.g., the way screens get refreshed after entering new data). Some managers compared HRMS to commercial soft ware and freeware. In any comparison, HRMS came out inferior. As one manager put it: "I've downloaded free soft ware off the Internet and figured out how to get it to work. But this particular tool [SSM] is so full of little icons that are completely befuddling to me." Indeed, IS experts do admit that HRMS has presented new technical challenges and that some implemented solutions are not technically elegant. The list of system maintenance requests demanded by the users contained hundreds of items at the time of this study.

Although striking in character, the usability problem is just the tip of the iceberg. The core problem lies elsewhere, and a number of respondents reflected on it. An aspect of the core problem is indicated in the following statement: "I personally feel, with the introduction of this application [SSM], that it has created more work for managers." The respondents also concurred that the extra work "is not value-adding" but "administrat ive" or "clerical." One respondent noted, "There have been two changes that have come simultaneously - the process change and the tool. So, the 
tool is maybe getting blamed for part of the process." Another agreed: "In some cases it is not necessarily the HRMS that's the problem, it's the way we're using the system." Since the users reject the new processes, they reject the system that runs the process.

Note that the company did not implement a formal business process reengineering prior to launching HRMS. Instead, both the system and the process were sold as a package deal. The users have reacted consistently by rejecting the whole package, even though some of them may have realized that the system has value. For managers, the most unat tractive aspect of the system is the electronic approval process. Instead of employing their secretaries to run checks of the staff's time and expenses and to provide documents ready for signing, managers using SSM have to run these checks on their own. This includes looking at the dat a in HRMS and, possibly, using some support documentation. Managers are supposed to finalize the process by marking appropriate checkboxes on the computer screen, which supplants the classical act of signing a business document. "IS this too difficult to do?" - rhet orically asks the champion of HRMS, an HR executive. The answer is obvious. However, this question/answer may obscure the fact that the previous steps in the approval process may not be as easy to perform. They take time and skill. The champion of HRMS points out that these approvals have always been a management responsibility. Although correct, this fact should be contrasted with the usual practice of managers' delegating parts of the approval processes to secretaries. This ritual was a public knowledge. It was part of the corporate culture and, specifically, infoculture since its content was the processing of staffreported data. The attempt to change this piece of infoculture via a self-service IS has been futile.

\section{Process Gaps}

That HRMS was implemented without a prior business process reengineering sets this system apart from typical implementations of ERP applications, although it is not a precedent (see Larsen \& Myers, 1999). From the perspective of system development in general and ERP systems in particular (Markus \& T anis, 2000), the bypass of BPR is a serious gap in the processes of system and corporate planning. Taking the perspective of Rogers's (2003) innovation diffusion process, gaps can again be seen in the early stages of the process. The first of the five stages called model agenda-setting was deficient. This is when an organization defines problems that may create a perceived need for innovation. What problem has Utilities Company tried to solve by automat ing the management approval process?

Corporate and HR executives put forward the goals of rationalizing administration, reduction of clerical staff (currently, $13 \%$ of company's employees), and saving on administrative costs. From the technological perspective, the rollout of new self-service HR applications follows the previous phase that resulted with HR applications for clerks. In a larger picture, HR applications add to the line of SAP implementations that has been spreading within the company for years and replacing a variety of old, unconnected systems. Links between the administration- and technologyrelated goals, however, were not explicated in terms of management's self-service when HRMS was planned. Scrutinized management analysis of expected work efficiency and HR issues resulting from management's self-service was also missing. As explained by an executive, an assumption evolved instead that better technology would be able to compensate for the clerks whose numbers would decrease gradually with retirement and cancellation of the vacated positions.

It follows from the discussion above that the self-service repercussions of defining strategic administrative and technological problems were never clearly addressed at the level of corporate divisions. This could explain why the self-service process was being sold bundled with the tool enabling it. In the mind of divisional management, this gap could trigger the question, what problem do self-service approvals solve? This question seemed to be on the lips of our respondents, who kept on point ing to problems that SSM did create, while never mentioning that the system 
solved any problem. In other words, the lack of clarity in the agenda-setting stage crept into the matching stage of the innovation process (Rogers, 2003.).

Ripple effects occurred even later in the process. The HRMS champions were somewhat caught by surprise by the adamant rejection of self-service processes when it had to be clarified who does what in the new division of labor and how different parties are specifically affected. This is the clarification stage in the innovation process (Rogers, 2003). If not passed successfully, adoption problems creep into the last (fifth) stage of routinizing an innovation, which is similar to the last stage in Markus and Tanis's (2000) ERP model. In sum, the gaps in processes that gave birth to HRMS contributed to the less than satisfactory adoption outcomes.

\section{Influence of Infoculture on HRMS Adoption}

Infoculture consists of beliefs, behaviors, and material artifacts that are related to information and IT . Infoculture is a part of organizational culture, influenced by it and influencing it. The present study identified a set of dimensions that are infocultural in character (Tables 1 and 2). Either these dimensions are derived from a broader corporate culture or they stand on their own, thus charting a distinctive sphere of infoculture. One of the derived infocultural aspects refers to atendency toward criticizing new things. It sifts into infoculture by making a new IS the object of criticism. Some of our interviewees argued that the people in their company "like to criticize and complain a lot." Criticizing is the first reaction to almost anything new that occurs in the corporate life. When the new thing is an IS, this custom drives attention to downsides of a new system, while pushing potential benefits out of the attention span. This is how the CEO indicated this phenomenon:

"I think that is true for sure that people like to criticize. A lot of it came about when we first introduced SAP because there was a difficult process then. There was a lot of resistance to change, an awful lot."

Depending on their place in the organization, members of the Utilities Company may think differently about the value of information, IT, and IS. Specifically, there is a clear polarization on a user and a technologist perspective (see T able 1). The two groups differ in terms of time perspective, valuing new technology and information, and understanding of HRMS purposes. While the users are concentrated on present work needs and expect HRMS to be merely an efficient work tool, technologist s are preoccupied with technological progress (see Table 1, rubric Fragmented Infoculture, it ems A, B, C). Further, there are slower and quicker adopters of systems, and the growth of casual users precipitated by self-service applications escalates challenges for the IS function (item D). The final dimension of technologists' infocult ure refers to an assumption that they are supposed to be in the driver's seat of a technology-organization development. This polarization indicates a significant fragmentation of the company's infoculture on two distinct subcultures (Martin, 1992). Technologists seem to feel sharply this gap:

"We don't seem to have the firm clout that a lot of organizations say, 'well listen, we're going to put this system in. I know it's going to create some problems, but you know this is where we're going, and just accept it and get on with life.' (IS executive)

The assumption of being in the driver's seat is interesting in itself. It surfaced in the statements of SAP people who described their actions in terms of "battles with them [division management]" and methods of assuring a win fortheir own design solutions, forecasting and shaping the future. The SAP people spoke about an inevitability of adopting best practices built into ERP systems and criticized technologically inert users' culture. The SAP managers had been in the position that allowed them to turn down requests for system customization and to configure HRMS for efficient maintenance even though users could be unhappy with the solutions. These technologists 
also made crucial development decisions that affected users in a major way (e.g., the selection of applications and of user interface details). Here is an illustration:

"Best practices are right, and you try to adopt them. And Ithink that's supposed to be the model that you're going for... We don't like to use the word 'customization'... With customization you go in and you change the code, and from that point on you have to support that yourself as you get new releases. You're really buying into the configuration versus customization."

Table 1. Criticizing, fragmentation, and shakeup

\section{Critical Bias}

- "People around here like to criticize and complain a lot." (HR Professional)

- " "Our culture is... 'if people don't like it, then change it right away'-type of thing." (IS Executive)

\section{Fragmented Infoculture}

Users: $\quad$ Technologists:

A) Shorter timeline, focus on present: "When we want the information, we usually want it right now; we don't want to make a phone call to find where they have hid it now." (supervisor)

B) New not necessarily better: "New and improved is not always better because there is a learning curve that goes go into each one." (manag er)

C) Purpose of HRMS: "Technology is only a tool. The people using the tool have to be able to take advantage of that tool." (manager)

"If I can't do it faster than I can manually, then there is no advantage to the technology to take over." (supervisor)
A) Longer Timeline, focus on future: "We went from not having any of these kinds of applications whatsoever to going into, and jumping in with both feet into some areas."

B) "Things will get better, as they did with the R/3 product... anything else that you do in this area."

C) "You have to really question people who insist that you have to do it the old way."

D) Pressure from Users: "There are thousands of people doing it rather than 200 super-users... And you try to do the best you can. This is normal business, eh?"

E) Assuming a Driver's Seat Role: "We picked the applications and those areas that we thought were the most important for the organization at this time..."

\section{Self Service Shakeup}

A) "The day that [SEE] was introduced, an employee got on it right away and was playing around. I got this work flow notification [...] but it wasn't easy to figure out what I was approving." (supervisor)

B) "For a number of folks who have now become time entry people it's a very different process. [...] We have seen some low accountability to make sure you do your time, make sure you are checking." (pro fessional)

C) "I know a lot of groups are trying to get that [self-service] down to the stafflevel, and that is probably something we could debate for a long time." (manager)

"I don't think the corporation as a whole is prepared to take it to everybody... [total self service] would be a hard change for people." (executive)

D) "But everyone should be doing their own expenses. You know what I mean - stop bitching and just do it." (clerk)

E) "It's not necessarily a system problem, but the change management that we've gone through to use the new system or in this case not use the new system." (supervisor) 
Overall, the disconnect in standpoints and expectations, which is captured in the category of infoculture, may be responsible for system design as well as for disconcerting adoption efforts that influenced the ext ent of adoption.

The self-service character of applications has stirred up a cultural shakeup. Values and practices of self-service are bubbling (items A and D in the last rubric of Table 1). These are countered by the traditional infoculture that feels challenged by the incipient self-service infoculture, generates ignorance (item A) and a lack of accountability (item B). When self-service is endorsed, the tradition triggers dilemmas regarding the limits of self-service (item $\mathrm{C}$ ).

The tension between the old and new infoculture is also manifested in the theme of change management that surfaced in many interviews (item E). Here is how technologists phrased it:

"The biggest problem or difficulty in the HR product was managing change. [...] There is always going to be people who are going to resist $[\ldots]$; if you can get $90 \%$ of them, you are doing great." (SAP expert)

"We haven't really locally put a process in to say "this is the way we're gonna do it". That's why I say it's not necessarily a system problem, but the change management that we've gone through to use the new system, or in this case not to use the new system." (supervisor)

However, change management is not merely a product of wishful thinking. In contrast to the broader organization, change management really happened in the HR department. Orchestrated efforts to adopt changes associated with HRMS reverberated from top to bottom of the department, engaging management, professionals, and clerks. For example, change management involved the introduction of a new vocabulary of system terms - an artifact of infoculture. A HR professional explains:

"We created some sample documentations or reference materials that folks could use. We had a little game within our group to say, 'Who is using the terminology the most,' and were getting points [for the use]. So, we tried to create some degree of excitement."

Early adopters of HRMS and self-service infoculture have endeavored to scale up adoption outside their function. In the process, they have used "a little nudging" on managers who fail to approve workflows on time. Carefully designed and maintained communication is a crucial component of change management - inside or out side a department, points out a HR manager:

"Change management is all about communication, $[\ldots]$ and making sure that people understand the need for the change, why we make the change, and then get buy-in. [...] Getting them engaged, communicating the urgency... listening to ongoing concerns and trying to make the system better... The system has to grow with us."

Utilities Company appears stretched between paper and electronic technology and information. Table 2 provides several compelling illustrations of this tension, coming from interviews across the corporation. Managers still prefer to see paper (see the rubric Dualism of Paper and Electronic Beliefs and Behaviors, item A). This could be due to personal preferences that may have to do with the managers' level of technical skills. Another factor could be the cost of going fully electronic: paper receipts needed for justifying expenses must be digitized before being entered in HRMS.

Another aspect of the paper-electronictension concerns values at tached to concepts of paperless office and administration (item B). One document that accompanied the process of HRMS development hailed a release of an application as a "nail in the coffin of paper-based administration." 
In reality, however, the dualism of paper and electronic persists. Adding to the list of possible causes are external instit utional pressures, as item $\mathrm{C}$ indicates. The government, business partners and other players may still require paper documents, thus animat ing this dualism. Unless the institutional environment changes, there may be no strong push for reducing the paper trail.

Table 2. Dualism, pace, and di vide

\section{Dualism of Paper and Electronic Trail}

A) "My boss still likes to see it all on paper."

- "I still print off the paper copy, and my manager still looks at that. So, when it comes time for him to have to approve it in the system, he has already seen on paper, and then it saves him time. I keep that signed copy for a long time."

- "Some hand in electronically, and some still hand in paper (time data). Because some gentlemen [supervisors and workers] are still not on the computer highway."

B) "We have added the idea that we are going to a paperless system, but we are printing off hundreds of employee's notifications of what they are paid."

C) "We are trying to go paperless but there are some times that paper still is a necessity."

\section{Systems Development Pace}

- "I think we'd all say that we all feel that we' re starting to get crippled with the computer." (supervisor)

- "I think we should take a look without jumping ahead too far all the time, take a look at solving some of these little issues and problems." (manager)

- "They just changed our portal and I can't find it [a tab for HRMS]. (manager)

Digital Divide

- "The majority of crewmembers do not have the network ID." (clerk)

- "You are treating some employees with a very nice product $[\ldots]$ and the other folks have to use the paper system or some other system that is much more cumbersome." (manager)

Systems Development Pace is a category that has strong support in the interview data. For example, a SAP tester and instructor argued that the company's applications are "never finished." He cited many examples demonstrating that functionality or user interface of various applications have not been brought to a desirable level of quality. More evidence appears in Table 2. Frustrated users believe that the pace of developing new systems and changing implemented ones exceeds their coping capabilities and even needs.

The last infocultural dimension relevant for HRMS adoption concerns a digital divide. The workers are deprived of access to HRMS and opportunities to advance their IT skills. This is how one clerk characterized the workers' situation:

"I work in a department of twenty people where sixteen of them are field workers. Ninety-nine percent of the time they don't have access to a computer, and when they do, they are not comfortable in using it."

Therefore, the workers have no time to do "computer work", since their workplace is wherever the construction site is. The company has not considered the use of wireless devices yet. Other clerks comment that workers may not even have the privilege to access the SSE module (Table 2). At any rate, the existence of have-nots sets long-term limits to the scope of self-service applications. 


\section{Conclusion: Mixed Messages}

In contrast to research that singles out customer satisfaction with direct and quick access to information, this case paints a less comforting picture. Overall, the story of HRMS conveys mixed messages. While the system adoption effort cannot be qualified as a failure that is frequently reported in the ERP/SAP literat ure (Bulkeley, 1996), the adoption rate is below the expected one after a year into the "shakedown phase" (Markus \& Tanis, 2000) or Rogers's (2003) clarification phase. Success measures reported by Stein and colleagues (2005) are not achieved - a reduction of administrative staff has been minimal and there has been no reduction of management HR duties. Although the SSE module is generally endorsed, the real key to HRMS adoption lies with the SSM module that is much less adopted mainly because it requires more work and technical skills on the managers' side. Without overcoming the resistance of SSM users-divisional managers and supervisors - the fut ure of HRMS is uncertain.

Evidence suggest s that HRMS suffers a plethora of usability problems. Using the terminology of the T echnology Acceptance Model (TAM) and the innovation framework respectively, it follows that HRMS exhibits a lower "perceived ease of use" (Davis, 1989) and a higher "complexity" (Rogers, 2003). HRMS does not deliver reports for executive decision making either. In the terminologies cited, this short coming indicates the system's lower "perceived usefulness" and a lower "relative advantage." But usability problems are the tip of the iceberg. This study determined that infoculture is a deeper problem that obstructs adoption of HRMS. The system pushes unfamiliar electronic workflows on divisional management. Using the terminology of Rogers's (2003) diffusion of innovation theory, SMM has low compatibility with past experiences and existing values of the adopters. In addition, HRMS challenges the old way of approving reported time and expense, in which clerks would do most of the dat a checking and some decision making for managers.

The IVO lenses portray divisional managers as followers of a particular sub-infoculture. Its hallmark is a focus on information rather than IT. Present time counts most in assessing benefits from an IS, and learning costs play a big part in assessing the value of new IT. Opposed to this is the infoculture heralded by the SAP unit, which boasts opposite assumptions: a new IT is always betterthan the old one, the fut ure merits more attention than the present time, and the organizational development should be shaped by IT. These differing infocultures create misunderstanding between the respective groups in the course of the system adoption process. While the business side tends to blame its counterpart for a lack of sensitivity for user needs, the technologist side may hastily characterize the users' legit imate concerns for system improvement as a roadblock to progress. This fragmentation of infoculture has analogues in the literature (Orlikowski \& Gash, 1994).

The corporate culture nurtures a critical bias that can potentially demerit any new technology, particularly among end-users. The situation is additionally aggravated by tensions between incipient values and practices of the self-service origin and the traditional infoculture. Regular data entry, rout inely logging into the system to check if there are employee reports awaiting approval, and performing entire tasks exclusively on electronic data - all these have been new practices for users to accept. Any cultural change is difficult, but it is even more so if it is not preceded by proper preparations. With the exception of the HR department, no systematic change management had been orchestrated. Most remarkably, BPR that would prepare management for processes embedde d in the SSM module was skipped. Utilities Company is not alone in this, but the damaging consequences are also shared (Larsen \& Myers, 1999). Being unprepared for change, many users

feel shaky or tend to circumvent the new processes, and managers have doubts about the desirable scope of self-service. 
The uncompromising electronic character of HRMS also challenges the existing infoculture in which electronic information and technology and their paper-bound counterpart co-exist. Contrary to Sarker and Lee's (2000) finding on dismantling "a sea of paperwork" with adoption of ERP, Utilities Company has maintained the old paper trail in parallel with the new electronic trail. Reasons are sometimes legal and imposed by the environment that still requests paper. But it is equally if not more detrimental, from the perspective of adopting HRMS, that "bosses still like to see it all on paper."There is the question of economic rationality ofthis dualism raised by an expert user and echoed in a number of interviews. The dualism annoys some users, while others appear indolent ("some hand time dat a electronically, and some still hand in paper"). At any rate, the paper-electronic dualism undermines the hope that HR applications are the once publicly touted "nail in the coffin of paper-based administration" and softens the motivation for adoption.

Many users feel as ifthey are run over by systems that develop at a relentless pace. There is a felling of perpetuating unfinished business, as not finalized applications are being pushed on users time and time again. This situation causes frustration and leaves some sour taste in the mouth. Clearly, the infoculture of users does not praise life with continual change. Such a perspective can hardly raise optimism in an adoption situation, and rejection may have set in as an automatic first response to any new application. This being the case, the current infoculture derails rational grasping and weighing of costs and benefits that underpin standard adoption models. In addition, this infoculture exhibits a digital divide, thus persistently keeping workers on the have-nots side.

Overall, the infoculture in Utilities Company hindered the HRMS before it could reach the last stage in the adoption process - rout ine use (Markus \& Tanis, 2000; Rogers, 2003). Unresolved problems may resurface and amplify in that last stage, bringing HRMS to either a compromised mode of use (Lapointe \& Rivard, 2005) or completely down (Lapointe \& Rivard, 2005; Rogers, 2003).

\section{Theoretical and Practical Contribution}

One limitation of this study is that it has captured only a six-month period of the adoption process in the company studied. A different time period of study would plausibly result in somewhat different insights. Still, this possibility does not invalidate the current results as they reflect a crucial moment in the life cycle of HRMS. Consequently, the study carries certain contributions to both academic research and management practice.

The theoretical contribution of this study refers to insights into cultural dynamics of adopting ERP self-service applications. The IVO-based inquiry unveiled multiple cultural dimensions that played part in adoption intentions of individual users of HRMS. The critical bias in organizational culture, fragmented infoculture, dualism between paper and electronic technology and practices, self-service challenges, perceived pace of systems development, and digital divide - all these are interesting dimensions with a potential of both helping to explain adoption of HRMS and adding to the system adoption theory that has been developed for systems out side the self-service category. The qualitative inquiry can be advanced and the quant it ative approaches can be adjusted for social factors that reside beyond the individual level of analysis.

For instance, the Technology Acceptance Model (T AM) (Davis, 1989; Davis et al., 1989) predicts that and individual's perceptions of the ease of using a system and of the system's usefulness determines the individual's intention to use the system. That this subjective weighing of costs and benefits is indeed at work as the antecedent to systems use has been proven in a plethora of studies. What remains invisible, however, is the influences from the broader organizational context on these individual valuations. Perception of characteristics of IT built into a system and the system-related information can be influenced by values and behaviors that evolve around information and IT. For example, if a particular group of users has a shorter time-focus in assessing 
the value of IT, praises quick access to data as the ultimate value, and believes that the speed of introducing new systems is inappropriately high, then these traits of infoculture can push down the assessment of a new system's usefulness. In Utilities Company, divisional managers and supervisors as well as some professionals share these beliefs. Similarly, if disliking to learn new IT skills while focusing on a new system's downsides are widely shared norms, the system's ease of use may be downgraded. By the same logic, an infoculture with opposite attributes, such as the one carried by the technologists, could push up a system's perceived usefulness and ease of use. To the same end do work the incipient praising of self-service and practical self-service determination of some end-users identified in the study. However, still more of counter-balancing forces are instantiated in the critical bias, persistence of papertrail, undesirable pace of systems development, and the persistent digital divide. Fut ure research needs to test the hypotheses that these and possibly other aspects of infoculture influence perceived ease of use and usefulness of IS. The infoculture of technologists in our case suggests that such relationship exist. Organizational culture and infoculture exist prior to individual perception of systems' advantages and disadvantages. Consequently, infoculture can be modeled as a moderat or to TAM's independent variables. Newer TAM models support this reasoning, as exemplified by the construct of social factors (Venkatesh, Morris, Davis, \& Davis, 2003). Moreover, our proposition on the influence of infoculture is congruent with Rogers's (2003) theory of innovation diffusion in which social norms have a prominent role.

The findings discussed can help practitioners to define strategic and tactical actions on increasing acceptance of self-service HR systems when the constellation of circumstances approximates the context of Utilities Company. As a quicker solution for advancing the adoption rate, one should take advantage of experiences and enthusiasm of early adopters (the HR staff and divisional clerks it this case). Creative techniques of adoption HR staff used could be spread to other parts of corporation. The early adopters may be turned into a social network tasked to assist diffusion of HRMS practices. Further, the executive management needs to revisit the question of potential benefits divisional management draws from a self-service system, when ambiguity is detected in this domain. On a longer run, the company's program of professional development for managers needs to incorporate the topic of managing by using electronic IS. As a complementary measure, the company should eliminate the paper documentation and paperwork wherever possible.

The HRMS champions may need to tone down their expectations and criticism. The start premise should be a realization that the changes in system-supported processes are not self-explanatory and natural. Further, both the technologists and business users need to make steps to bridge the gap separat ing them. A point of departure should be learning about the other side's perspective. Moreover, organizational interfaces that can facilitate this mutual learning between users and technologists (business analysts and users, developers and users) need to be revisited in terms of responsibility and expected deliverables. Finally, licensing costs aside, the digital divide that bars the majority of employees (workers) from self-service applications is untenable in the age when new generations use computers as toys and needs to be considered by executives.

In conclusion, self-service systems that increasingly are deployed in organizations bring up challenges to adoption theory and practical management. These facts suggest that there is a need for new research approaches and for a dedicated line of research.

\section{References}

Bhappu, A., \& Shultze, U. (2006). The role of relational and operational performance in B2B customers' adoption of sel f-service technology. Journal of Service Research 8(4), 3712-385.

Bressand, A., \& Distler, C. (1995). La planéte relationelle. Paris: Flamarion.

Bulkeley, W. M. (1996, November 18). When things go wrong. The Wall Street Journal, p. R25. 
Charmaz, K. (2006). Constructing grounded theory. London: Sage.

Curran, J., Meuter, M., \& Suprenat, C. (2003). Intentions to use self-service technologies: A confluence of multiple attitudes. Journal of Service Research 3(5), 209-224.

Dabholkar, P., Bobbitt, L., \& Lee, E. (2003). Understanding consumer motivation and behavior related to self-scanning in retailing: Implications for strategy and res earch on technology-based sel f-service. International Journal of Service Industry Management, 14, 59-95.

Davenport, T., \& Prusak, L. (1997). Information ecology: Mastering information and knowledge environment. New York: Oxford University Press.

Davis, F. (1989). Perceived usefulness, perceived eas e of use, and user acceptance of in formation technology. MIS Quarterly, 13(3), 320-340.

Davis, F., Bagozzi, R., \& Warshaw, P. (1989). User acceptance of computer technology: A comparison of two theoretical models. Management Science, 35(8), 982-1003.

Glasser, B., \& Strauss, A. (1967). The discovery of grounded theory. Chicago: Aldine.

Huang, J., Newell, S., Galliers, R., \& Pan, S. (2003). Dangerous liaisons? Component based development and organizational subcultures. IEEE Transactions of Engineering Management, 50(1), 89-99.

Kaarst-Brown, M., \& Robey, D. (1999). More on myth, magic and metaphor: Cultural insights into the management of in formation technology in organizations. Information Technology and People, 12(2), 192-217.

Krumbholz, M., \& Maiden, M. (2001). The implementation of enterprise resource planning pack ages in different organizational and national cultures. Information Systems, 26(3), 185-204.

Lapointe, L., \& Rivard, S. (2005). A multilevel model of resistance to information technology implementation. MIS Quarterly, 29(3), 461-491.

Larsen, M., \& Myers, M. (1999). When success turns into failure: A pack age-driven business process reengineering project in the financial services industry. Journal of Strategic Information Systems, 8, 395417.

Lee, A. (1989). A scientific methodology for MIS case studies. MIS Quarterly, 13(1), 33-50.

Leidner, D., \& Kayworth, T. (2006). A review of culture in information systems research: Toward a theory of in formation technology culture conflict. MIS Quarterly, 30(2), 357-399.

Markus, M. L., \& Tanis, C. (2000). The enterprise systems experience: From adoption to success. In R.W. Zmud (Ed.), Framing the domains of IT research: Glimpsing the future through the past (pp. 173-205). Cincinnati, OH: Pinnaflex Educational Resources.

Martin, J. (1992). Cultures in organizations: Three perspectives. New York: Ox ford University Press.

Orlikowski, W. (1992). The duality of technology: Rethinking the concept of technology in organizations. Organization Science, 3(3), 398-427.

Orlikowski, W. (1996). Evolving with Notes: Organizational change around groupware technology. In C. Ciborra (Ed.), Groupware and teamwork: Invisible hand or technical hindrance? (pp. 23-59). Chichester: John Wiley.

Orlikowski, W., \& Gash, D. (1994). Technological fram es: Making sense of IT in organizations. ACM Transactions on Information Systems, 12(2), 174-207.

Rogers, E. (2003). Diffusion of innovations (5th ed.). New York: Free Press.

Sarker, S., \& Lee, A. (2000). Using a case study to test the role of three key social enablers in ERP implementation. In S. Ang, H. Krcmar, W. Orlikowski, P. Weill, \& J. I. DeGross (Eds.), Proceedings of the 21st International Conference on Information Systems (pp. 414-425), December 10-13, 2000 Brisbane, Australia. 
Stein, A, Hawking, P., \& Wyld, D.. (2005). B2E SAP portals: Employee self-s ervice case study. In L. Lau, Managing business with SAP: Planning, implementation and evaluation (pp. 90-109). Hershey, PA: Idea Group.

Suchman, L. (1987). Plans and situated actions: The problem of human-machine communication. Cambridge, UK: Cambridge University Press.

Tedlock, B. (2000). Ethnography and ethnographic repres entation. In N. Denzin \& Y. Lincoln (Eds.), The handbook of qualitative research (pp. 455-486). Thousand Oaks, CA: Sage.

Travica, B. (2005a). Inform ation politics and information culture: A Case Study. Informing Science Journal 8, 211-244. Retrieved from http://inform.nu/Articles/Vol8/v8p211-244Travica.pdf

Travica, B. (2005b). Information view of org anization. Journal of International Technology and Information Management, 14(3), 2005, 1-20.

Travica, B. (2007). Of monsters, divinations, costly dumbness and fumbling: Adopting a self-service system. Journal of Information, Information Technology, and Organizations, 2, 15-29. Retrieved from http://iiito.org/articles/JIITOv2p015-029T ravica258.pdf

Venkatesh, V., Morris, M. G., Davis, G. B., \& Davis, F. D. (2003). User acceptance of information technology: Toward a unified view. MIS Quarterly, 27(3), 425-478.

Yin, R. (2003). Case study research: Design and methods (3rd ed.). Thousand Oaks, CA: Sage.

\section{Biography}

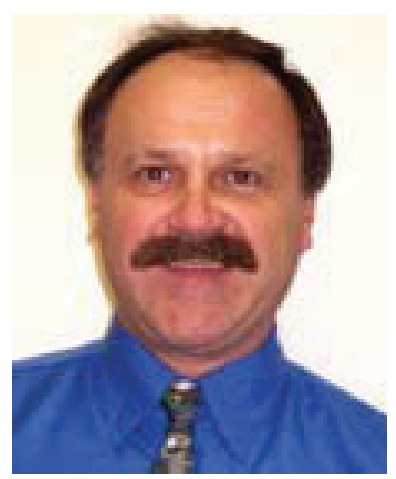

Bob Travica teaches information systems at University of Manitoba, and investigates organizations from the perspective of information and information technology management. His current preoccupations are with advancing the information view of organization as a framework for research and teaching. 